\title{
Ski prevents TGF- $\beta$-induced EMT and cell invasion by repressing SMAD-dependent signaling in non-small cell lung cancer
}

\author{
HAIPING YANG ${ }^{1,2^{*}}$, LEI ZHAN ${ }^{1,2 *}$, TIANJIE YANG ${ }^{1,2^{*}}$, LONGQIANG WANG $^{1,2}$, CHANG LI $^{2,3}$, \\ $\mathrm{JUN}_{\mathrm{ZHAO}}{ }^{2,3}, \mathrm{ZHE} \mathrm{LEI}^{1,2}, \mathrm{XIANGDONG} \mathrm{LI}^{3}$ and HONG-TAO ZHANG ${ }^{1,2}$ \\ ${ }^{1}$ Soochow University Laboratory of Cancer Molecular Genetics, Medical College of Soochow University, \\ and ${ }^{2}$ Suzhou Key Laboratory for Molecular Cancer Genetics, Suzhou, Jiangsu 215123; \\ ${ }^{3}$ Department of Neurosurgery, The First Affiliated Hospital, Soochow University, \\ Medical College of Soochow University, Suzhou, Jiangsu 215006, P.R. China
}

Received February 16, 2015; Accepted March 13, 2015

DOI: 10.3892/or.2015.3961

\begin{abstract}
Epithelial-mesenchymal transition (EMT) is a key event in cancer metastasis, which confers cancer cells with increased motility and invasiveness, and EMT is characterized by loss of epithelial marker E-cadherin and gain of mesenchymal marker N-cadherin. Transforming growth factor- $\beta$ (TGF- $\beta$ ) signaling is a crucial inducer of EMT in various types of cancer. Ski is an important negative regulator of TGF- $\beta$ signaling, which interacts with SMADs to repress TGF- $\beta$ signaling activity. Although there is accumulating evidence that Ski functions as a promoter or suppressor in human types of cancer, the molecular mechanisms by which Ski affects TGF- $\beta$-induced EMT and invasion in non-small cell lung cancer (NSCLC) are not largely elucidated. In the present study, we investigated the mechanistic role of Ski in NSCLC metastasis. Ski was significantly reduced in metastatic NSCLC cells or tissues when compared with non-metastatic NSCLC cells or tissues. Moreover, following TGF- $\beta$ stimulation Ski-silenced A549 cells had more significant features of EMT and a higher invasive activity when compared with A549 cells overexpressing Ski. Mechanistically, Ski-silenced and overexpressed A549 cells showed an increase and a reduc-
\end{abstract}

Correspondence to: Dr Hong-Tao Zhang, Soochow University Laboratory of Cancer Molecular Genetics, Medical College of Soochow University, 199 Ren'ai Road, Sino-Singapore Industrial Park, Suzhou, Jiangsu 215123, P.R. China

E-mail: htzhang@suda.edu.cn

Dr Xiangdong Li, Department of Neurosurgery, The First Affiliated Hospital of Soochow University, 188 Shizi Street, Suzhou, Jiangsu 215006, P.R. China

E-mail: xdlijia@aliyun.com

${ }^{*}$ Contributed equally

Key words: non-small cell lung cancer, Ski, TGF- $\beta /$ Smad signaling, epithelial-mesenchymal transition, invasion tion in the SMAD3 phosphorylation level, respectively. This was supported by plasminogen activator inhibitor-1 (PAI-1) promoter activity obtained in Ski-silenced and overexpressed A549 cells. However, after treatment of SIS3 (inhibitor of SMAD3 phosphorylation) followed by TGF- $\beta 1$ stimulation, we did not observe any effect of Ski on TGF- $\beta$-induced EMT, and invasion in Ski-silenced and overexpressed A549 cells. In conclusion, our findings suggest that Ski represses TGF- $\beta$ induced EMT and invasion by inhibiting SMAD-dependent signaling in NSCLC.

\section{Introduction}

A major reason for mortality from solid tumors, including non-small cell lung cancer (NSCLC), is cancer metastasis (1). Epithelial-mesenchymal transition (EMT) is a crucial early event during metastasis. In the process of EMT, cells dissolve cadherins and tight junctions, lose cell polarity and exhibit multiple mesenchymal cell properties such as becoming more motile and invasive (2).

Transforming growth factor- $\beta$ (TGF- $\beta$ ) plays various roles in the process of malignant progression (3), and was initially identified as an important inducer of EMT (4). In the canonical SMAD-dependent signaling, TGF- $\beta$ binds to the cell membrane surface type II TGF- $\beta$ receptor (TGF $\beta$ R2) which then recruits the type I TGF- $\beta$ receptor (TGF $\beta R 1$ ) and activates its serine/threonine protein kinase. Thus, activated TGF $\beta R 1$ leads to phosphorylation of SMAD2 and SMAD3. Activated SMAD2 and SMAD3 interact with SMAD4 to form a transcriptional complex that translocates into the nucleus to regulate the expression of specific genes (5). As a hallmark of TGF- $\beta$-induced EMT, an increased expression of E-cadherin and a decreased expression of $\mathrm{N}$-cadherin are closely associated with TGF- $\beta$-induced phosphorylated SMAD3 $(6,7)$. In addition, TGF- $\beta$ activated MAP kinase (8), Rho-like GTPase (9) and phosphatidylinositol-3-kinase (PI3K)/AKT non-SMAD pathways during TGF- $\beta$-induced EMT (10).

As a member of the Ski family, the c-Ski protein was encoded by the $S K I$ gene in humans and first termed by investigators 
from Sloan-Kettering Institute (11). Notably, Ski directly interacts with the SMAD complex to prevent the phosphorylation of SMAD2/3 and block the TGF- $\beta$ signaling pathway (12-14). In addition to interacting with SMAD proteins, Ski functions as a direct antagonist of TGF $\beta$ R1 (15). Ski was also identified to interact with non-SMAD signaling, including Akt (16) and p38 signaling (17) pathways. The abovementioned findings suggested that Ski is involved in SMAD-dependent and -independent TGF- $\beta$ signaling pathways.

Given that TGF- $\beta$ signaling mediates cytostasis (3) and Ski is a key negative regulator of TGF- $\beta$ signaling (18), Ski expression was found to be elevated in several types of cancer, including melanoma, esophageal, colorectal and pancreatic cancer, and leukemia, suggesting that Ski plays an oncogenic role in cancer (19-23). By contrast, Shinagawa et al reported that $\mathrm{Ski}^{+} /$mice increased the susceptibility of chemical-induced tumorigenesis, suggesting that Ski is a tumor-suppressor (24). Wang et al found that Ski suppressed tumor metastasis in pancreatic cancer (25). Although Ski has particular roles in the tumor development and progression, to the best of our knowledge, few studies have focused on the functions of Ski in lung cancer. In view of the role of TGF- $\beta$ signaling in cell EMT or invasion, Ski may act as a tumor metastasis suppressor by inhibiting the TGF- $\beta$ signaling pathway and have a close relationship with the metastasis and recurrence of human types of cancer, including NSCLC. However, the effect of Ski on TGF- $\beta$-induced EMT and cell invasion in NSCLC remains to be determiend.

In the present study, we found that the expression of Ski was significantly lower in metastatic NSCLC than non-metastatic cells. Moreover, Ski mRNA expression was downregulated in NSCLC tissues from patients with lymph-node or distance metastasis. Mechanistically, Ski inhibited TGF- $\beta$-induced EMT and cell invasion by repressing SMAD-dependent signaling in NSCLC.

\section{Materials and methods}

Cell culture. Human A549, LTEP- $\alpha-2$, 95C and 95D NSCLC cell lines were purchased from the Cell Bank of the Chinese Academy of Science. The cells were cultured in Roswell Park Memorial Institute (RPMI)-1640 medium (HyClone, Logan, UT, USA) with $50 \mathrm{U} / \mathrm{ml}$ each of penicillin and streptomycin, and $10 \%$ heat-inactivated fetal bovine serum (FBS) in humidified incubators at $37^{\circ} \mathrm{C}$ with $5 \% \mathrm{CO}_{2}$.

NSCLC tissue samples. Forty-six paired NSCLC tissues and adjacent non-cancerous lung tissues were obtained after informed consent from patients in the First Affiliated Hospital of Soochow University. NSCLC patients had not received chemotherapy or radiotherapy prior to tissue sampling. According to whether NSCLC patients had local lymph-node or distance metastasis, NSCLC tissue samples were classified into the non-metastatic (NOM0) and metastatic (N1-2 and/or M1) groups. The tissues were snap-frozen and stored in an ultra-deep freezer at $-80^{\circ} \mathrm{C}$. The present study was approved by the Academic Advisory Board of Soochow University.

Reagents and antibodies. Human recombinant TGF- $\beta 1$ was purchased from R\&D Systems Inc. (Minneapolis, MN, USA).
TGF- $\beta 1$ was diluted in sterile $4 \mathrm{mM} \mathrm{HCl}$ containing $1 \mathrm{mg} / \mathrm{ml}$ bovine serum albumin (BSA). Antibodies used for western blot analysis were as follows: mouse anti-E-cadherin and anti-N-cadherin (BD Biosciences, Franklin Lakes, NJ, USA), rabbit anti-SMAD3, anti-phospho-SMAD3 (Cell Signaling Technology, Inc., Danvers, MA, USA), rabbit anti-Ski and mouse anti- $\beta$-actin (Abcam, San Francisco, CA, USA), and anti-mouse/ rabbit secondary antibodies (Santa Cruz Biotechnology, Inc., Santa Cruz, CA, USA). SIS3 (a special inhibitor of SMAD3 phosphorylation) was purchased from Santa Cruz Biotechnology.

Lentivirus production, transduction and generation of stable cell lines. The full-length coding sequence region of human SKI gene was amplified by PCR using the primers: forward, 5'-CCGCTCGAGGAGCCGGAGCGCACCATGGAGG-3' and reverse, 5'-CGCGGATCCAAACACTCGCTTGGTA ATAGGCAC-3'). It was then cloned into a lentivirus expression vector $\mathrm{pLVX}$-IRES-Neo with restriction endonucleases XhoI and BamH1 (underscored) to generate a pLVX-IRESNeo-Ski plasmid, which was in turn co-transfected with three packaging plasmids (Lenti-THT packaging mix) (both from Clontech Laboratories, Inc., San Francisco, CA, USA) into 293T cells using Lipofectamine 2000 (Life Technologies, Carlsbad, CA, USA). The empty pLVX-IRES-Neo vector was used as a negative control (Mock). After 48-h transient transfection, the lentivirus-containing supernatant was collected and applied to infect A549 cells. After 48 h, the stable cells were selected with $400 \mu \mathrm{g} / \mathrm{ml}$ of G418. To obtain a stable Ski knockdown A549 cell line, we synthesized a small hairpin RNA (shRNA) containing a 19-bp interfering sequence (25) against SKI transcript: 5'-TGATGAAAGAGGCCAACGAG TTCAAGAGACTCGTTGGCCTCTTTCATCTTTTTTC-3', and cloned it into a lentiviral vector pLentiLox3.7 (pLL3.7) with restriction endonucleases $H p a \mathrm{I}$ and XhoI to generate a pLL3.7-sh-Ski vector. A scrambled sequence, 5'-TGTTCTCCG AACGTGTCACGTTTCAAGAGAACGTGACACGTTCG GAGAACATTTTTTC-3', was designed as a negative control shRNA. Using Lipofectamine 2000, the pLL3.7-sh-Ski vector or negative control vector was in turn co-transfected with two lentiviral package plasmids (pVSVG and p $\Delta 8.9$ ) into $293 \mathrm{~T}$ cells and the packaged lentiviruses were harvested $48 \mathrm{~h}$ later for subsequent A549 infection. The infected A549 cells were cultured and the monoclonal stable cells were selected by EGFP and verified by western blotting.

Reporter gene construct and luciferase assays. The TGF- $\beta 1-$ inducible luciferase reporter plasmid (PAI-1-pGL3-Luc) containing the SMAD-binding elements of the plasminogen activator inhibitor-1 (PAI-1) gene promoter region were generated as previously described (7). This plasmid was transfected into cells using Lipofectamine 2000. After 6-h transfection, TGF- $\beta 1$ ( $5 \mathrm{ng} / \mathrm{ml})$ was added for $24 \mathrm{~h}$, and the luciferase activity was determined by the Dual-Luciferase Reporter Assay kit (Promega Corporation, Madison, WI, USA).

Western blot analysis. Cells were lysed using a RIPA lysis buffer (Cell Signaling Technology, Inc.) with protease inhibitor and phosphatase inhibitor cocktails (Sigma, St. Louis, MO, USA). Following centrifugation at $12,000 \mathrm{rpm}$ for $15 \mathrm{~min}$, the 


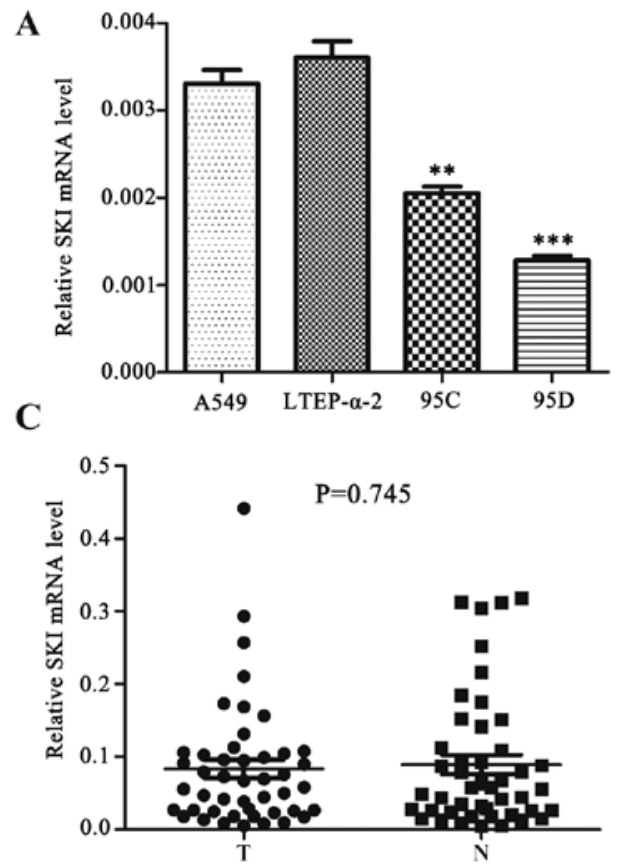

B
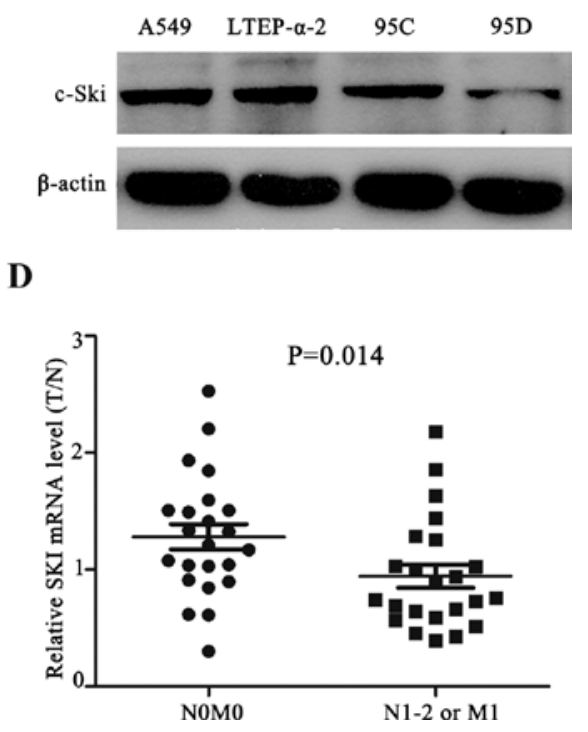

Figure 1. Expression of Ski is reduced in metastatic NSCLC cells and tissues. (A) RT-qPCR analysis of relative Ski mRNA levels in A549, LTEP- $\alpha-2,95 C$ and 95D cells. Ski mRNA levels are expressed as a relative index normalized against $\beta$-actin. (B) Western blot analysis of Ski protein levels in A549, LTEP- $\alpha$-2, 95C and 95D cells. $\beta$-actin was used as an internal control. (C) RT-qPCR analysis of relative Ski mRNA expression in 46 paired NSCLC tissues (T) and paired non-cancer lung tissues (N). (D) The mRNA levels of Ski in non-metastatic and metastatic NSCLC tissues (N0M0 vs. N1-2 and M1). N, lymph node metastasis; $\mathrm{M}$, distal metastasis. $\mathrm{y}$-axis is the fold-change of T/N expression ratio of Ski mRNA. Data are presented as the mean $\pm \mathrm{SD}$ from three independent experiments, and each was conducted in triplicate. ${ }^{*} \mathrm{P}<0.05 ;{ }^{* * *} \mathrm{P}<0.001$. NSCLC, non-small cell lung cancer.

total protein products in the collected supernatant were separated by SDS-PAGE under reducing condition and transferred to a nitrocellulose membrane (Millipore, Bedford, MA, USA). The membrane was blocked with $1 \%$ BSA/TBST buffer for $1 \mathrm{~h}$ at room temperature and incubated with primary antibodies overnight at $4^{\circ} \mathrm{C}$. The membranes were washed three times in TBST buffer and incubated with HRP-conjugated secondary antibodies for $2 \mathrm{~h}$ at room temperature. Protein detection was performed using the enhanced chemiluminescence system (ECL; Pierce, Rockford, IL, USA). Experiments were performed in triplicate and normalized by the expression of $\beta$-actin.

RNA extraction and reverse transcription-quantitative PCR $(R T-q P C R)$. When cells were grown to $80 \%$ confluence on 6-well plates, total RNA was isolated using RNAiso Plus kit (Takara Bio, Inc., Otsu, Japan) according to the manufacturer's instructions. Synthesis of cDNA with reverse transcriptase was conducted using an M-MLV First Strand kit (Invitrogen, Carlsbad, CA, USA). The concentration of total RNA and cDNA were measured on a NanoDrop 2000 spectrophotometer (Thermo Fisher Scientific, Waltham, MA, USA). RT-qPCR was performed using Platinum SYBR-Green qPCR SuperMixUDG kit (Invitrogen) according to the manufacturer's instructions on ABI Prism 7500 Sequence Detection System (Applied Biosystems, Foster City, CA, USA). $\beta$-actin was used as an internal control for mRNA qualification and the $2^{-\Delta \Delta \mathrm{Ct}}$ method was applied in the analysis of the quantitative data. The primers used for RT-qPCR were: Ski, 5'-CGACGTGAA GGAGAAATTCG-3' (forward), and 5'-GGACTGGGAAGA GGTGTCAT-3' (reverse) (25); MMP-2, 5'-TGATCTTGACCA
GAATACCATCGA-3' (forward), and 5'-GGCTTGCGAGGG AAGAAGTT-3' (reverse).

Cell invasion assay. Cell invasion assay was performed using Transwell plates (BD Biosciences) with polycarbonate filters of $8-\mu \mathrm{m}$ pore size. Matrigel (Discovery Labware, Bedford, MA, USA) was used to coat the upper surface of the filter in each of the upper chamber. Cells $\left(5 \times 10^{4}\right)$ with serum-free RPMI-1640 were seeded in the upper chambers. In each lower chamber, 20\% FBS medium was placed as a chemoattractant. After $6 \mathrm{~h}$, the cells were stimulated with $5 \mathrm{ng} / \mathrm{ml}$ TGF- $\beta 1$. After $24 \mathrm{~h}$ incubation, the cells on the upper surface of the filter membrane were wiped and the invaded cells on the lower surface were then fixed in $100 \%$ methanol and stained with $1 \%$ crystal violet. Three microscopic fields (magnification, $\mathrm{x} 100)$ were photographed and counted/chamber, and results presented as the mean $\pm \mathrm{SD}$ of results from three replicate experiments.

Statistical analysis. For the cell lines, data were analyzed using an unpaired t-test (two-tailed) to determine statistically significant differences between two groups. Comparisons between clinicopathological characteristics and expression ratios $(\mathrm{T} / \mathrm{N})$ of Ski mRNA in tissue samples were performed with non-parametric tests (Mann-Whitney $U$ test for two groups, Kruskall-Wallis test for three or more groups). Data were presented as mean \pm standard deviation (SD). $\mathrm{P}<0.05$ was considered to indicate a statistically significant result. The statistical analysis was performed using GraphPad Prism software version 5.0 (GraphPad Software Inc., San Diego, CA, USA). 
A

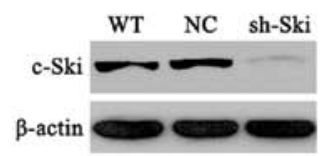

B
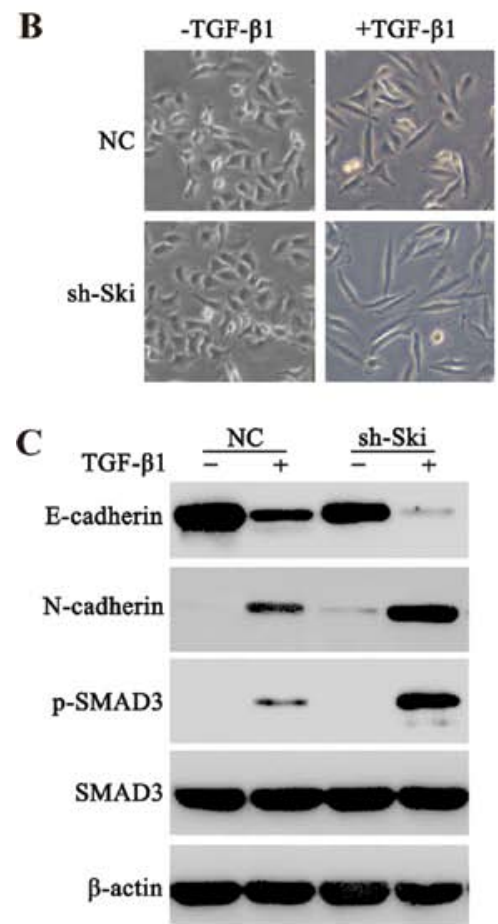

D

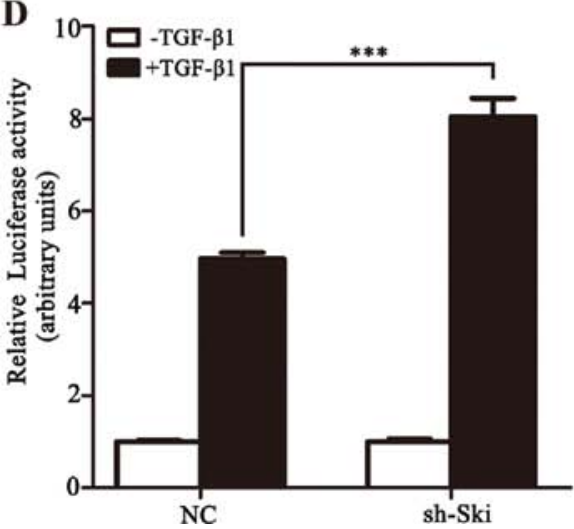

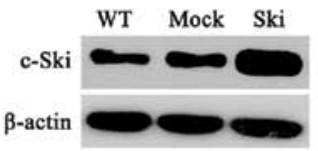
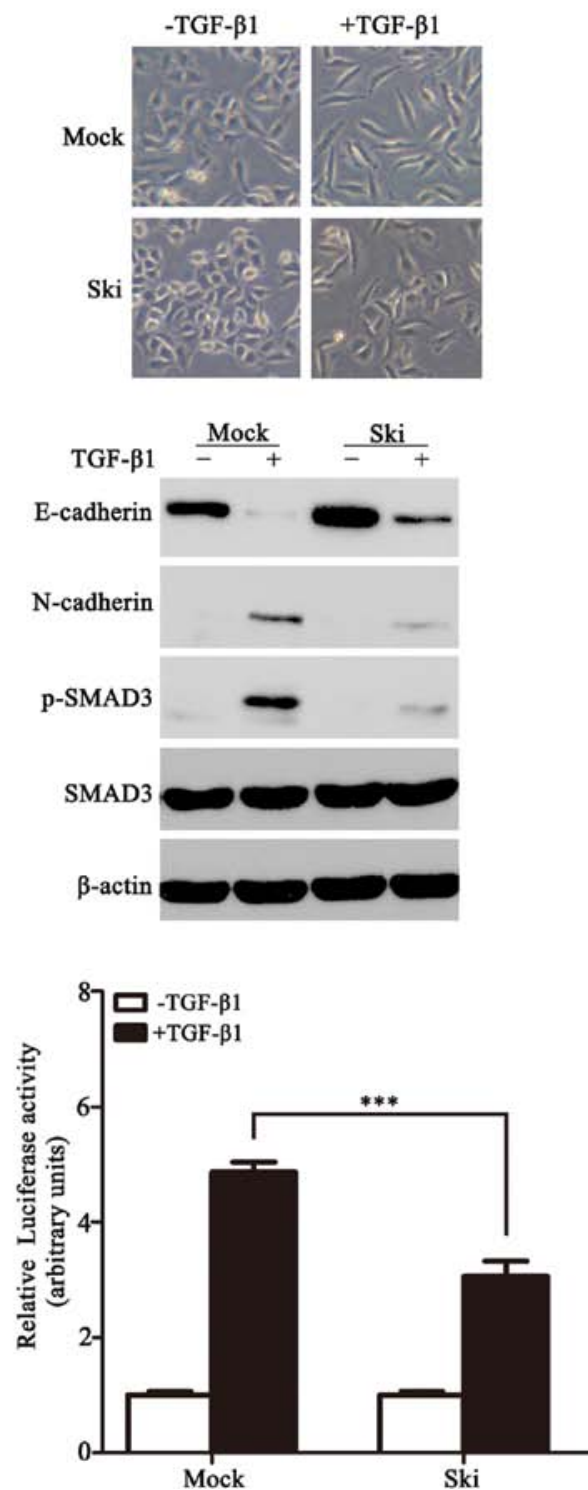

Figure 2. Ski significantly prevents TGF- $\beta 1$-induced EMT and TGF- $\beta 1$-activated transcriptional response. (A) Expression of Ski protein in stable Ski-silenced A549 cells (A549-sh-Ski) and Ski-overexpressed A549 cells (A549-Ski). (B) After being serum-starved for $24 \mathrm{~h}$, A549-sh-Ski and A549-Ski cells were treated with or without $5 \mathrm{ng} / \mathrm{ml} \mathrm{TGF}-\beta 1$ for $24 \mathrm{~h}$, respectively. Cell morphology was examined and photographed using a phase-contrast microscope. (C) A549-sh-Ski and A549-Ski cells were treated as above. The protein levels of E-cadherin, N-cadherin, SMAD3 and p-SMAD3 were determined by western blotting. (D) A549-sh-Ski and A549-Ski cells transfected with PAI-1 promoter luciferase constructs were incubated for $24 \mathrm{~h}$ in the absence or presence of $5 \mathrm{ng} / \mathrm{ml}$ TGF- $\beta 1$, and then subjected to luciferase assays as described in Materials and methods. Relative reporter activity is normalized to that of pGL3-basic reporter. ${ }^{* * * *} \mathrm{P}<0.001$. TGF- $\beta 1$, transforming growth factor- $\beta 1$; EMT, epithelial-mesenchymal transition; p-SMAD3, phosphorylated-SMAD3; PAI-1, plasminogen activator inhibitor-1.

\section{Results}

Skiexpressionisreducedinmetastatic NSCLCcellsandtissues. To examine whether the expression of Ski is associated with NSCLC, we determined Ski expression in a panel of NSCLC cell lines, including A549 and LTEP- $\alpha-2$ (lung adenocarcinoma cell lines), $95 \mathrm{C}$ (low metastatic giant-cell lung carcinoma cell line) and 95D (high metastatic giant-cell lung carcinoma cell line). We found that the mRNA and protein levels of Ski were reduced in 95C and 95D cells, particularly in 95D cells, when compared with A549 and LTEP- $\alpha-2$ (Fig. 1A and B).
We then detected Ski mRNA expression in 46 paired NSCLC tissues $(\mathrm{T})$ and adjacent cancer-free lung tissues $(\mathrm{N})$. As shown in Fig. 1C, no significant difference in Ski mRNA level was observed between NSCLC and paired adjacent cancer-free lung tissues $(\mathrm{P}=0.745)$. However, after classifying NSCLCs by metastatic status into two groups (N0M0 vs. N1-2 and/or M1), we found that the ratio of Ski mRNA level $(\mathrm{T} / \mathrm{N})$ was significantly lower in the metastatic group (N1-2 and/or M1) than the non-metastatic group (NOM0) ( $\mathrm{P}=0.014$; Fig. 1D). The results suggested that Ski played a tumor metastasis-suppressing role in NSCLC. 
A
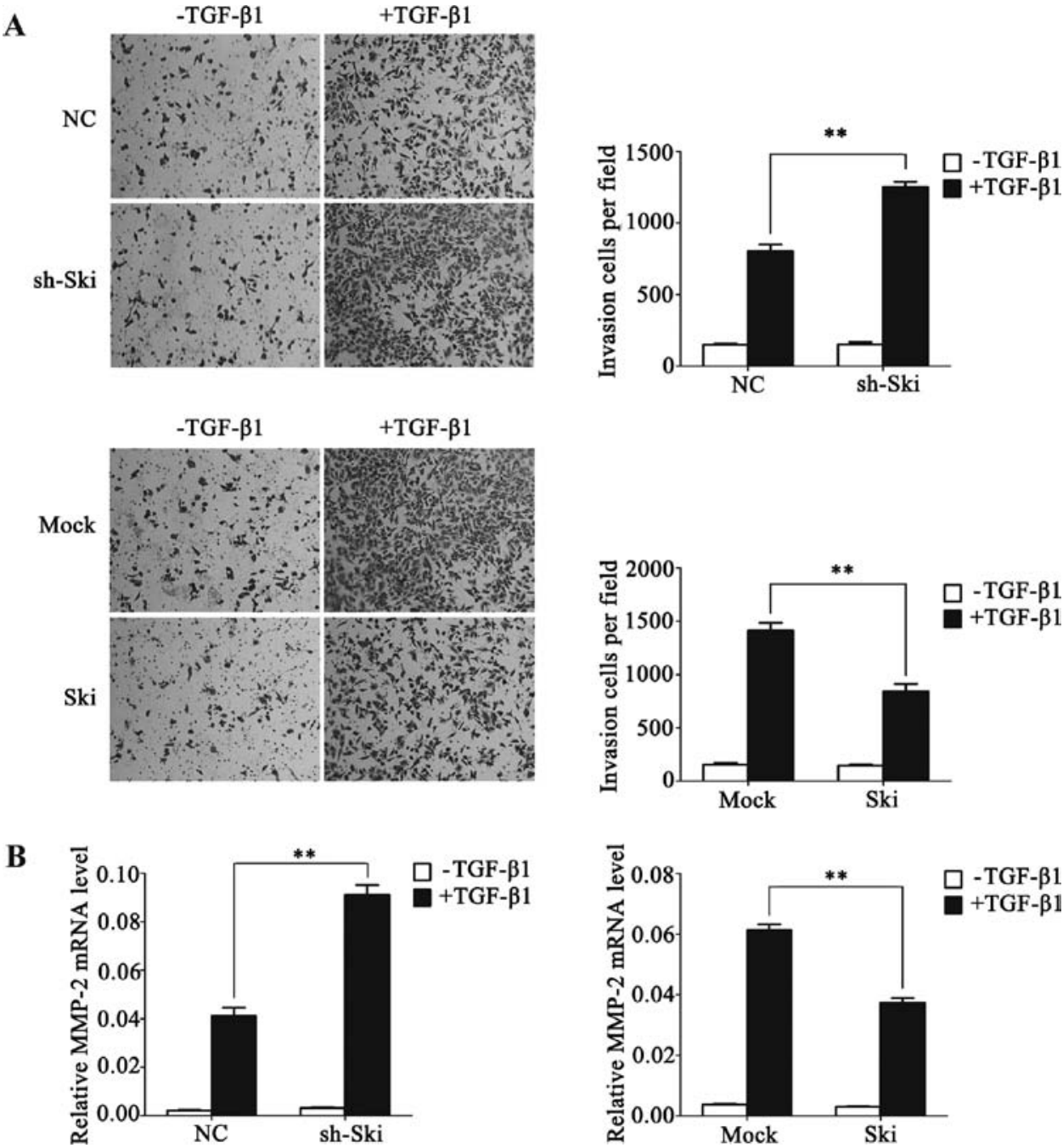

Figure 3. Ski inhibits TGF- $\beta 1$-mediated cell invasion in A549 cells. (A) A Transwell assay was performed for the effect of Ski on TGF- $\beta 1$-mediated cell invasion. A549-sh-Ski and A549-Ski stable cells were plated onto Matrigel pre-coated Transwell chambers in the presence or absence of $5 \mathrm{ng} / \mathrm{ml}$ TGF- $\beta 1$ for $24 \mathrm{~h}$, and allowed to invade through an $8-\mu \mathrm{M}$ pore in Transwells. Invasive cells through the pores were stained and counted in at least three microscopic fields (magnification, x100). (B) After being serum-starved for $24 \mathrm{~h}$, A549-sh-Ski and A549-Ski cells were incubated with $5 \mathrm{ng} / \mathrm{ml}$ TGF- $\beta 1$ for $24 \mathrm{~h}$, and MMP-2 mRNA levels were determined by RT-qPCR. ${ }^{* *} \mathrm{P}<0.01$. TGF- $\beta 1$, transforming growth factor- $\beta 1$.

Ski inhibits TGF- $\beta$-induced EMT and TGF- $\beta$-mediated transcriptional response in NSCLC cells. To elucidate the function of Ski involved in TGF- $\beta$-induced EMT in vitro, we first generated A549 monoclonal cells with stable knockdown of Ski (A549-sh-Ski) and overexpression of Ski (A549-Ski) (Fig. 2A). Following TGF- $\beta 1$ stimulation, the A549 cell clones exhibited a spindle-shaped and fibroblast-like morphology and exhibited an EMT phenotype. Notably, Ski-silenced A549 cells had more significant features of EMT when compared with A549 cells overexpressing Ski (Fig. 2B). Moreover, we examined the expression of TGF- $\beta$-induced EMT markers (E-cadherin and $\mathrm{N}$-cadherin) in the two stable clones, and found that in the presence of TGF- $\beta 1$, A549-sh-Ski cells exhibited decreased E-cadherin and increased $\mathrm{N}$-cadherin when compared with control stable cells (Fig. 2C, left panel), whereas an opposite result was observed in the A549-Ski cells (Fig. 2C, right panel). To determine whether Ski affects TGF- $\beta$-mediated activation of SMAD3 in EMT, we examined the phosphorylated-SMAD3 (p-SMAD3) level. In response to TGF- $\beta 1$, A549-sh-Ski and A549-Ski cells showed an increase and a reduction in the p-SMAD3 level, respectively (Fig. 2C), indicating that Ski represses the TGF- $\beta$-induced phosphorylation of SMAD3 in NSCLC cells. This result was supported by PAI-1 promoter activity obtained in A549-sh-Ski or A549-Ski cells. As shown in Fig. 2D, PAI-1 promoter activity was high in A549-sh-Ski cells but low in A549-Ski cells. The findings demonstrated that Ski significantly inhibited TGF- $\beta$-induced EMT and TGF- $\beta /$ SMAD-mediated transcriptional response in NSCLC cells.

Ski represses TGF- $\beta$-induced cell invasion in NSCLC cells. Given the fact that the acquisition of an enhanced invasion is one of the hallmarks of TGF- $\beta$-induced EMT in development and disease (2), and our above findings suggested that Ski represses TGF- $\beta$-inducible EMT, we determined whether Ski affected tumor invasiveness in A549 cells. To assess this, Matrigelcoated Transwell assays were performed in A549-sh-Ski and A549-Ski cells in the presence or absence of TGF- $\beta 1$. As a result, following TGF- $\beta 1$ stimulation, A549-sh-Ski cells invading through Matrigel were significantly enhanced when compared with control cells although A549-Ski cell invasive ability was attenuated (Fig. 3A). Furthermore, we found that Ski apparently weakened the TGF- $\beta$-induced expression of 
$\mathbf{A}$

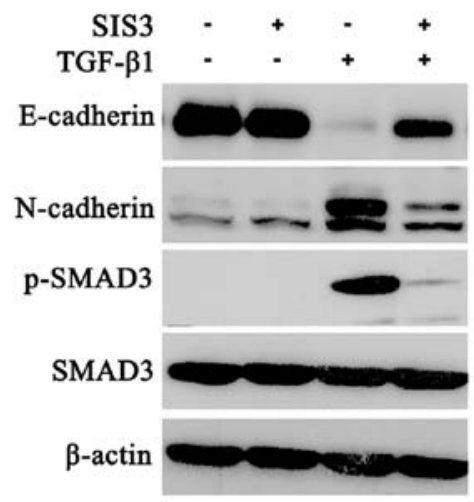

B
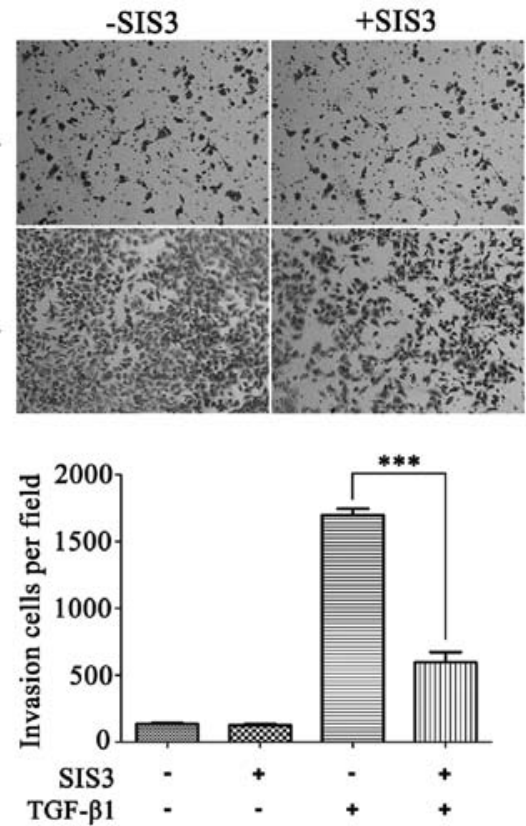

Figure 4. p-SMAD3 plays a vital role in TGF- $\beta 1$-induced EMT and cell invasion. (A) Repression of p-SMAD3 significantly attenuated TGF- $\beta 1$-induced EMT. After being pre-treated with $3 \mu \mathrm{M}$ SIS3 for $6 \mathrm{~h}$, A549 cells were exposed to $5 \mathrm{ng} / \mathrm{ml}$ TGF- $\beta 1$ for 24 h. The levels of E-cadherin, N-cadherin, p-SMAD3 and SMAD3 were determined by western blotting. (B) The effect of p-SMAD3 inactivation on TGF- $\beta 1$-induced cell invasion. A549 cells were plated onto Matrigel pre-coated Transwell chambers. After being treated with $3 \mu \mathrm{M}$ SIS 3 for $6 \mathrm{~h}$, A549 cells were incubated with $5 \mathrm{ng} / \mathrm{ml}$ TGF- $\beta 1$ for $24 \mathrm{~h}$. Invasive cells were stained and counted in at least three microscopic fields (magnification, $\mathrm{x} 100$ ). ${ }^{* * *} \mathrm{P}<0.001 . \mathrm{p}-\mathrm{SMAD} 3$, phosphorylated-SMAD3; TGF- $\beta 1$, transforming growth factor- $\beta 1$; EMT, epithelial-mesenchymal transition.

MMP-2, which was widely recognized as an enhancer of cell invasion (Fig. 3B). Collectively, the results indicated that Ski played an inhibitory role in TGF- $\beta$-induced cell invasion in NSCLC cells, supporting our observation that Ski expression was downregulated in metastatic NSCLC cells and tissues.

Ski prevents TGF- $\beta$-induced EMT and cell invasion by inhibiting SMAD-dependent TGF- $\beta$ signaling in NSCLC. The above findings suggested the involvement of Ski in TGF- $\beta$-induced EMT and invasion by SMAD-dependent signaling. Other non-SMAD signaling pathways can also be activated during TGF- $\beta$-induced EMT $(26,27)$. To exclude the possibility that Ski is involved in non-SMAD pathways affecting TGF- $\beta$-induced EMT and invasion in NSCLC, we first used SIS3, a specific inhibitor of SMAD3 phosphorylation, to block the TGF- $\beta$ /SMAD canonical pathway in A549 cells. As shown in Fig. 4A, SIS3 markedly reduced the TGF- $\beta$-induced p-SMAD3 level, restored E-cadherin expression and weakened $\mathrm{N}$-cadherin expression. Moreover, SIS3 significantly repressed TGF- $\beta$-induced invasion in A549 cells (Fig. 4B). The results suggested that p-SMAD3 was essential for TGF- $\beta$-induced EMT and cell invasion in NSCLC.

Following the pre-treatment of SIS3 followed by TGF- $\beta 1$ stimulation, A549-sh-Ski or A549-Ski cells did not demonstrate any significant changes of $\mathrm{E}$ - and $\mathrm{N}$-cadherin expression compared with their corresponding control cells (Fig. 5A). Similarly, Ski knockdown or overexpression did not exert any significant effect on the invasive ability of A549 cells in the presence of SIS3 and TGF- $\beta 1$ (Fig. 5B). The results therefore indicated that Ski affected TGF- $\beta$-induced EMT and cell invasion by inhibiting SMAD-dependent TGF- $\beta$ signaling.

\section{Discussion}

Lung cancer has a high morbidity and mortality tumor worldwide and nearly $~ 85 \%$ of all lung cancers belong to NSCLC (28). Most cancer deaths are due to tumor metastasis, which promotes to make a switch of early-stage tumors into invasive malignancies (1). Therefore, understanding the molecular basis of tumor metastasis is necessary for cancer diagnosis and treatment. EMT is a fatal event during tumor metastasis (29). As a well-known EMT inducer, TGF- $\beta$ plays an important role in tumor metastasis (27). Ski was reported to function as a negative regulator of TGF- $\beta$ signaling (18). However, the role of Ski in TGF- $\beta$-induced EMT and invasion was poorly understood in NSCLC. In the present study, our findings show that Ski expression was lower in metastatic NSCLC cells and tissues than the non-metastatic ones. Of note, we identified that Ski prevents TGF- $\beta$-induced EMT and cell invasion through the SMAD-dependent pathway in NSCLC cells.

Ski was primarily identified to serve as an oncogene by promoting anchorage-independent growth of chicken and quail embryo fibroblast cells (30). Subsequently, Ski was reported to be a prognostic factor in TGF- $\beta$-positive advanced gastric cancer and promote tumor growth in diffuse-type gastric carcinoma $(31,32)$. In the present study, no significant difference in the Ski expression level was found between NSCLC tissues and paired adjacent non-cancer lung tissues. However, we detected that the downregulated expression of Ski was significantly associated with NSCLC metastasis. The results support those of Le Scolan et al who reported that a reduced Ski expression in lung cancer cells enhances tumor metastasis in vivo (33). Thus, Ski appears to function as a metastasis suppressor in NSCLCs. Nevertheless, Javelaud 
A $\quad$ SIS 3
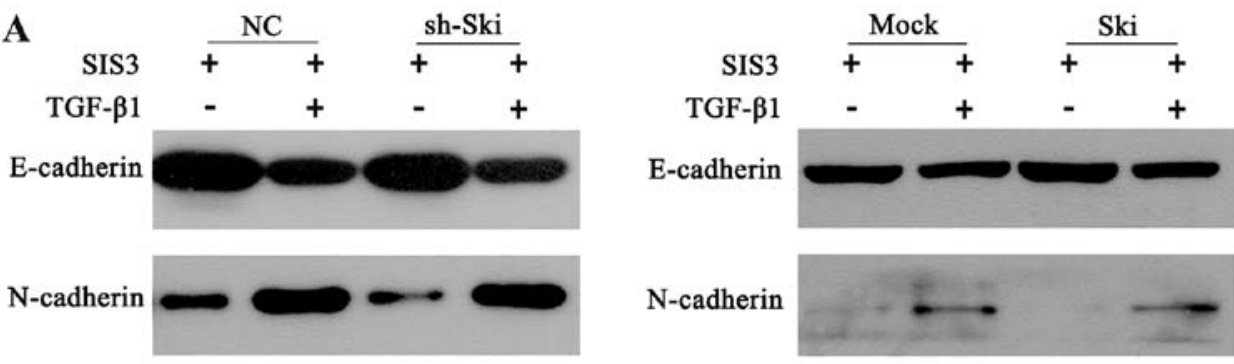

N-cadherin

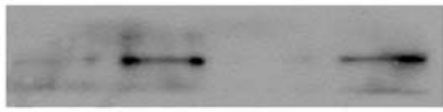

$\beta$-actin

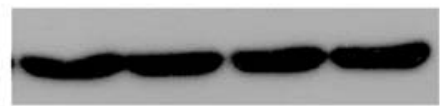

$\beta$-actin

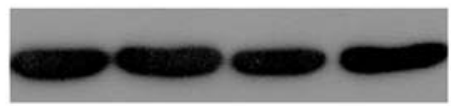

B

SIS3

SIS3+TGF- $\beta 1$
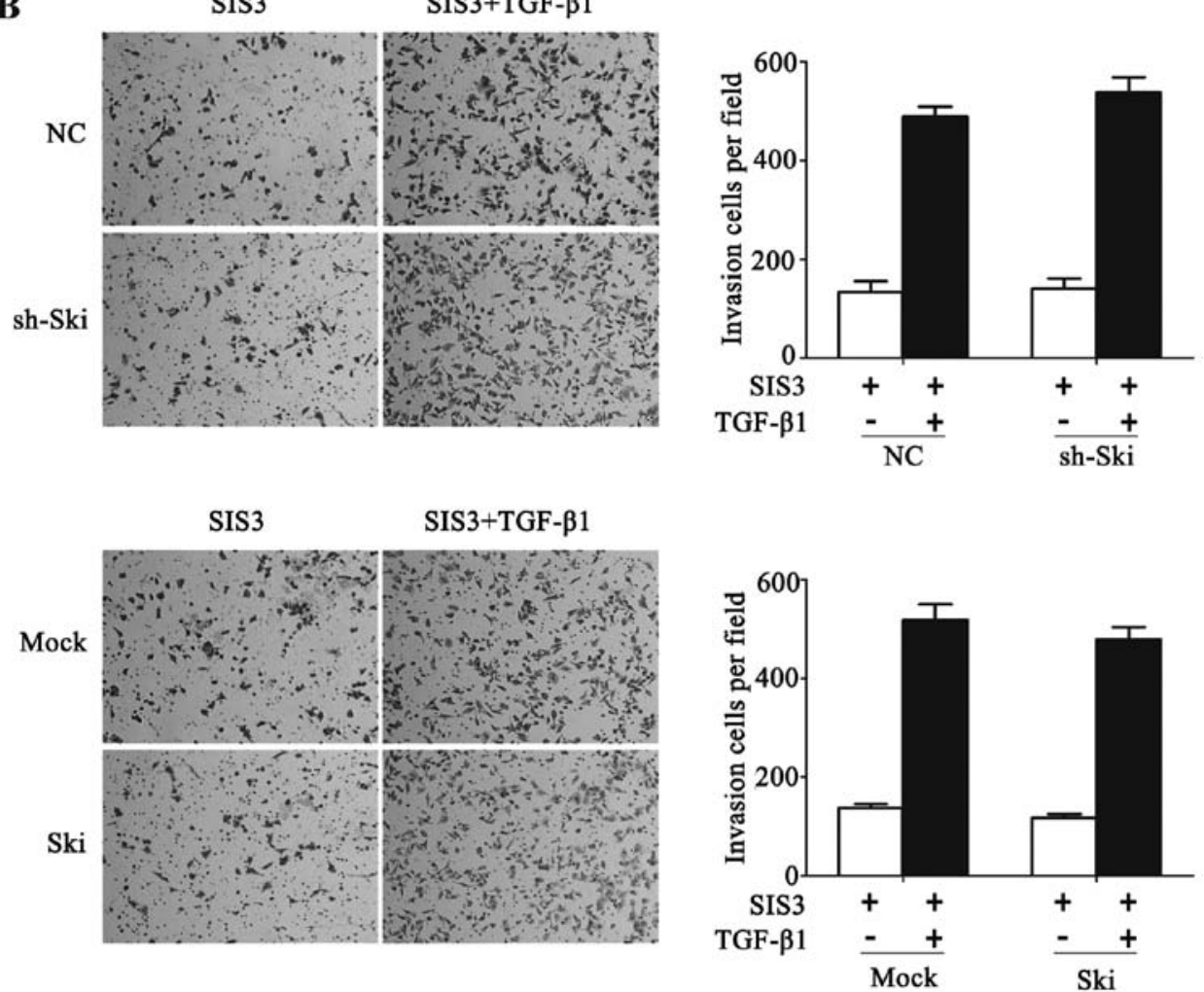

Figure 5. Ski inhibits TGF- $\beta 1$-induced EMT and cell invasion by repressing SMAD-dependent signaling. (A) Repression of p-SMAD3 abrogated the effect of Ski on TGF- $\beta 1$-induced EMT. A549-sh-Ski and A549-Ski stable cells were pre-treated with $3 \mu \mathrm{M}$ SIS3 for $6 \mathrm{~h}$, and then exposed to $5 \mathrm{ng} / \mathrm{ml}$ TGF- $\beta 1$ for $24 \mathrm{~h}$. The levels of E- and N-cadherin were determined by western blotting. (B) The blocking phosphorylation of SMAD3 abrogated the effect of Ski on TGF- $\beta 1$-induced invasion. After being pre-treated with $3 \mu \mathrm{M}$ SIS3 for $6 \mathrm{~h}$, A549-sh-Ski and A549-Ski cells were treated with or without $5 \mathrm{ng} / \mathrm{ml}$ TGF- $\beta 1$ for $24 \mathrm{~h}$. Invasive cells were stained and counted in at least three microscopic fields (magnification, $\mathrm{x} 100$ ). TGF- $\beta 1$, transforming growth factor- $\beta 1$; EMT, epithelial-mesenchymal transition; p-SMAD3, phosphorylated-SMAD3.

et al observed that there was no correlation between Ski and melanoma metastasis (34). These data suggest that Ski functions differently depending on the stages of tumor progression and tumor types.

Although there are various roles of Ski playing in cancer development and progression, the molecular mechanisms by which Ski influences TGF- $\beta$-induced EMT and cell invasion in NSCLC are not largely understood. Specifically, the knockdown of Ski significantly altered the expression levels of EMT-related genes in breast cancer cells (33), suggesting that Ski is involved in EMT. In the present study, we found that Ski significantly inhibited TGF- $\beta$-induced EMT and invasion in NSCLC cells. This is not surprising since TGF- $\beta$ promotes EMT through a combination of SMAD-dependent and
SMAD-independent pathways $(26,27)$, and Ski interacts with these signaling pathways. Recently, Wang et al reported that the knockdown of Ski significantly enhanced TGF- $\beta$-induced EMT in SMAD4-deficient pancreatic cancer cells (25). That finding suggests that Ski regulates TGF- $\beta$-induced EMT through non-SMAD pathways in pancreatic cancer. By contrast, our findings revealed that Ski was not invovled in non-SMAD pathways affecting TGF- $\beta$-induced EMT and invasion in NSCLC. However, Ski repressed TGF- $\beta$-induced EMT and invasion by inhibiting SMAD-dependent signaling in NSCLC.

In conclusion, to the best of our knolwedge, this is the first study to show that Ski is downregulated in metastatic NSCLC cells and tissues. Moreover, cell-based and biochemical assays 
indicate that Ski prevents TGF- $\beta$-induced EMT and cell invasion by repressing the canonical SMAD signaling. Our findings that Ski expression inhibits NSCLC cell invasion by controlling TGF- $\beta /$ Smad signaling, and provide new insights into therapeutic strategies for NSCLC metastasis.

\section{Acknowledgements}

The present study was supported in part by §grants from the National Natural Science Foundation of China (81372277 and 81171894 to H.-T. Zhang), the Jiangsu Province's Key Provincial Talents Program (RC2011106 to J. Zhao), the Jiangsu Province's Outstanding Medical Academic Leader Program (LJ201138), the '333' Project of Jiangsu Province Government (to H.-T. Zhang), the Graduate Innovation Project of Jiangsu Province (CXZZ13_0830 to Z. Lei), the Soochow Scholar Project of Soochow University (to H.-T. Zhang), the Suzhou Key Laboratory for Molecular Cancer Genetics (SZS201209 to H.-T. Zhang), and A Project Funded by the Priority Academic Program Development of Jiangsu Higher Education Institutions (PAPD).

\section{References}

1. Gupta GP and Massagué J: Cancer metastasis: Building a framework. Cell 127: 679-695, 2006.

2. Thiery JP, Acloque H, Huang RY and Nieto MA: Epithelialmesenchymal transitions in development and disease. Cell 139: 871-890, 2009

3. Pasche B: Role of transforming growth factor beta in cancer. J Cell Physiol 186: 153-168, 2001.

4. Miettinen PJ, Ebner R, Lopez AR and Derynck R: TGF-beta induced transdifferentiation of mammary epithelial cells to mesenchymal cells: Involvement of type I receptors. J Cell Biol 127: 2021-2036, 1994.

5. Massagué J: How cells read TGF-beta signals. Nat Rev Mol Cell Biol 1: 169-178, 2000.

6. Roberts AB, Tian F, Byfield SD, Stuelten C, Ooshima A, Saika S and Flanders KC: Smad3 is key to TGF-beta-mediated epithelialto-mesenchymal transition, fibrosis, tumor suppression and metastasis. Cytokine Growth Factor Rev 17: 19-27, 2006.

7. Liu RY, Zeng Y, Lei Z, Wang L, Yang H, Liu Z, Zhao J and Zhang HT: JAK/STAT3 signaling is required for TGF- $\beta$-induced epithelial-mesenchymal transition in lung cancer cells. Int $\mathbf{J}$ Oncol 44: 1643-1651, 2014.

8. Yan Z, Winawer S and Friedman E: Two different signal transduction pathways can be activated by transforming growth factor beta 1 in epithelial cells. J Biol Chem 269: 13231-13237, 1994.

9. Edlund S, Landström M, Heldin $\mathrm{CH}$ and Aspenström P. Transforming growth factor-beta-induced mobilization of actin cytoskeleton requires signaling by small GTPases Cdc42 and RhoA. Mol Biol Cell 13: 902-914, 2002.

10. Bakin AV, Tomlinson AK, Bhowmick NA, Moses HL and Arteaga CL: Phosphatidylinositol 3-kinase function is required for transforming growth factor beta-mediated epithelial to mesenchymal transition and cell migration. J Biol Chem 275: 36803-36810, 2000.

11. Li Y, Turck CM, Teumer JK and Stavnezer E: Unique sequence, ski, in Sloan-Kettering avian retroviruses with properties of a new cell-derived oncogene. J Virol 57: 1065-1072, 1986.

12. Akiyoshi $\mathrm{S}$, Inoue $\mathrm{H}$, Hanai J, Kusanagi $\mathrm{K}$, Nemoto $\mathrm{N}$, Miyazono K and Kawabata M: c-Ski acts as a transcriptional co-repressor in transforming growth factor-beta signaling through interaction with smads. J Biol Chem 274: 35269-35277, 1999.

13. Luo K, Stroschein SL, Wang W, Chen D, Martens E, Zhou S and Zhou Q: The Ski oncoprotein interacts with the Smad proteins to repress TGFbeta signaling. Genes Dev 13: 2196-2206, 1999.
14. Xu W, Angelis K, Danielpour D, Haddad MM, Bischof O, Campisi J, Stavnezer E and Medrano EE: Ski acts as a co-repressor with Smad2 and Smad3 to regulate the response to type beta transforming growth factor. Proc Natl Acad Sci USA 97: 5924-5929, 2000.

15. Ferrand N, Atfi A and Prunier C: The oncoprotein c-Ski functions as a direct antagonist of the transforming growth factor- $\beta$ type I receptor. Cancer Res 70: 8457-8466, 2010.

16. Band AM, Björklund M and Laiho M: The phosphatidylinositol 3 -kinase/Akt pathway regulates transforming growth factor- $\beta$ signaling by destabilizing ski and inducing Smad7. J Biol Chem 284: 35441-35449, 2009.

17. Li J, Li P, Zhang Y, Li GB, Zhou YG, Yang K and Dai SS: c-Ski inhibits the proliferation of vascular smooth muscle cells via suppressing Smad3 signaling but stimulating p38 pathway. Cell Signal 25: 159-167, 2013.

18. Luo K: Ski and SnoN: Negative regulators of TGF-beta signaling. Curr Opin Genet Dev 14: 65-70, 2004

19. Reed JA, Bales E, Xu W, Okan NA, Bandyopadhyay D and Medrano EE: Cytoplasmic localization of the oncogenic protein Ski in human cutaneous melanomas in vivo: Functional implications for transforming growth factor beta signaling. Cancer Res 61: 8074-8078, 2001.

20. Fukuchi M, Nakajima M, Fukai Y, Miyazaki T, Masuda N, Sohda M, Manda R, Tsukada K, Kato H and Kuwano H: Increased expression of c-Ski as a co-repressor in transforming growth factor-beta signaling correlates with progression of esophageal squamous cell carcinoma. Int J Cancer 108: 818-824, 2004.

21. Buess M, Terracciano L, Reuter J, Ballabeni P, Boulay JL, Laffer U, Metzger U, Herrmann R and Rochlitz C: Amplification of $S K I$ is a prognostic marker in early colorectal cancer. Neoplasia 6: 207-212, 2004.

22. Heider TR, Lyman S, Schoonhoven R and Behrns KE: Ski promotes tumor growth through abrogation of transforming growth factor-beta signaling in pancreatic cancer. Ann Surg 246: 61-68, 2007.

23. Ritter M, Kattmann D, Teichler S, Hartmann O, Samuelsson MK, Burchert A, Bach JP, Kim TD, Berwanger B, Thiede C, et al: Inhibition of retinoic acid receptor signaling by Ski in acute myeloid leukemia. Leukemia 20: 437-443, 2006.

24. Shinagawa T, Nomura T, Colmenares C, Ohira M, Nakagawara A and Ishii S: Increased susceptibility to tumorigenesis of skideficient heterozygous mice. Oncogene 20: 8100-8108, 2001.

25. Wang $P$, Chen Z, Meng ZQ, Fan J, Luo JM, Liang W, Lin JH, Zhou ZH, Chen H, Wang K, et al: Dual role of Ski in pancreatic cancer cells: Tumor-promoting versus metastasis-suppressive function. Carcinogenesis 30: 1497-1506, 2009.

26. Derynck R and Akhurst RJ: Differentiation plasticity regulated by TGF-beta family proteins in development and disease. Nat Cell Biol 9: 1000-1004, 2007.

27. Massagué J: TGFbeta in Cancer. Cell 134: 215-230, 2008.

28. Lei Z, Liu RY, Zhao J, Liu Z, Jiang X, You W, Chen XF, Liu X, Zhang K, Pasche B, et al: TGFBRI haplotypes and risk of nonsmall-cell lung cancer. Cancer Res 69: 7046-7052, 2009.

29. Kang Y and Massagué J: Epithelial-mesenchymal transitions: Twist in development and metastasis. Cell 118: 277-279, 2004.

30. Colmenares $C$ and Stavnezer E: The ski oncogene induces muscle differentiation in quail embryo cells. Cell 59: 293-303, 1989.

31. Nakao T, Kurita N, Komatsu M, Yoshikawa K, Iwata T, Utsunomiya T and Shimada M: Expression of thrombospondin-1 and Ski are prognostic factors in advanced gastric cancer. Int $\mathrm{J}$ Clin Oncol 16: 145-152, 2011.

32. Kiyono K, Suzuki HI, Morishita Y, Komuro A, Iwata C, Yashiro M, Hirakawa K, Kano MR and Miyazono K: c-Ski overexpression promotes tumor growth and angiogenesis through inhibition of transforming growth factor-beta signaling in diffuse-type gastric carcinoma. Cancer Sci 100: 1809-1816, 2009.

33. Le Scolan E, Zhu Q, Wang L, Bandyopadhyay A, Javelaud D, Mauviel A, Sun L and Luo K: Transforming growth factor-beta suppresses the ability of Ski to inhibit tumor metastasis by inducing its degradation. Cancer Res 68: 3277-3285, 2008.

34. Javelaud D, van Kempen L, Alexaki VI, Le Scolan E, Luo K and Mauviel A: Efficient TGF- $\beta$ /SMAD signaling in human melanoma cells associated with high c-SKI/SnoN expression. Mol Cancer 10: 2, 2011. 